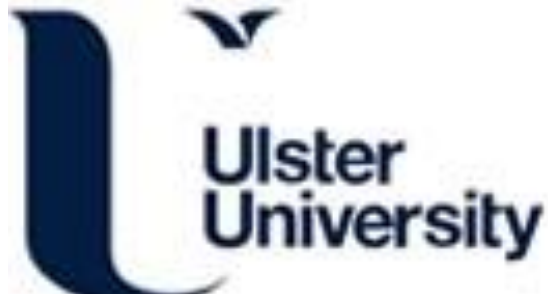

The spatial and temporal dynamics of infrastructure development disparity - From assessment to analyses

Rana, I. A., Bhatti, S. S., \& e Saqib, S. (2017). The spatial and temporal dynamics of infrastructure development disparity - From assessment to analyses. Cities, 63, 20-32. https://doi.org/10.1016/j.cities.2016.12.020

Link to publication record in Ulster University Research Portal

Published in:

Cities

Publication Status:

Published (in print/issue): 01/03/2017

DOI:

10.1016/j.cities.2016.12.020

Document Version

Author Accepted version

\section{General rights}

Copyright for the publications made accessible via Ulster University's Research Portal is retained by the author(s) and / or other copyright owners and it is a condition of accessing these publications that users recognise and abide by the legal requirements associated with these rights.

\section{Take down policy}

The Research Portal is Ulster University's institutional repository that provides access to Ulster's research outputs. Every effort has been made to ensure that content in the Research Portal does not infringe any person's rights, or applicable UK laws. If you discover content in the Research Portal that you believe breaches copyright or violates any law, please contact pure-support@ulster.ac.uk. 
Cities

Volume 63, March 2017, Pages 20-32 (published online: 12 January 2017)

http://www.sciencedirect.com/science/article/pii/S026427511630302X

doi: $10.1016 /$ j.cities.2016.12.020

\title{
The spatial and temporal dynamics of infrastructure development disparity - From assessment to analyses
}

Irfan Ahmad Rana, Saad Saleem Bhatti, Shahab e Saqib

\begin{abstract}
Infrastructure development relies on the allocation of resources which is usually uneven across cities. Socioeconomic instability stems from such development disparity that consequently affects the decision processes focusing on sustainable development. This study proposes an approach to examine the temporal dynamics of infrastructure development disparity at multiple spatial scales. Starting from the selection of spatial scales, time-series and infrastructure development indicators fitting the study requirements, the Infrastructure Development Index (IDI) values are computed through sequential steps involving data normalization and assessment of indicator weights through analytic hierarchy process. The sectoral, IDI and disparity analyses are then carried out using coefficient of variance $\left(C_{v}\right)$, temporal $I D I$ value change, and $C_{v} /$ sample t-test methods, respectively. The methodology was applied to a case study area, the five city districts (Faisalabad, Gujranwala, Lahore, Multan and Rawalpindi) of the province of Punjab, Pakistan, at town, city district and province scales (the province scale encompassed only the five city districts). Three time periods (2002, 2007 and 2012) and five infrastructure development indicators were considered. The results show that the development status in Lahore (provincial capital) was better compared to the other city districts. The temporal trend, however, indicated that the provision of infrastructure facilities has improved in the study area over the past years. The proposed methods performed quite well at identifying the development gaps at multiple spatial scales, though the approach can be enhanced by incorporating more indicators.
\end{abstract}

Keywords: disparity analysis; infrastructure development index; multi-scale; primary and secondary cities; Punjab; spatiotemporal

\section{Introduction}

Development disparity can be defined as an unequal distribution of resources with respect to an area or population, and is considered unfavorable for economic growth (Rouf \& Jahan, 2007). It is seen as a pressing issue in the modern world as it promotes social injustice and environmental degradation. Infrastructure is one of the core sectors which directly or indirectly determines the socioeconomic development condition of a region (Holtz-Eakin \& Schwartz, 1995). World Bank delivered evidences that infrastructure played a crucial role in urban transformation (Kessides, 1993). Moreover, substantial linkages have been found between infrastructural services and socioeconomic development (Esfahani \& Ramírez, 2003; Mangone, 2016). Coordinated infrastructure projects are thus considered to offer balanced and stable regional development between urban and rural areas in terms of social welfare, economy and environment (Mangone, 2016; Shen, Jiang, \& Yuan, 2012).

Urbanization is viewed as a negative thing by some researchers (Gordon \& Richardson, 2000; Habibi \& Asadi, 2011), while others consider it positive for regional development (B. Roberts \& Kanaley, 2006). Rapid population rise and haphazard urban development often results in a decrease in open spaces, urban decay, increase in land prices and transportation costs, unemployment and 
degradation of environment (Gordon \& Richardson, 2000; Jaeger, Bertiller, Schwick, \& Kienast, 2010) - some researchers, however, have also identified a positive relationship between urbanization and human development (Njoh, 2003). On the other hand, metropolitans/cities are seen as embodiments of civilization and engines of economic development (Pelling, 2003), and are therefore favored over secondary cities and other urban settlements in general (B. H. Roberts, 2014). However, the important thing is to strike a balance between urban growth and quality of life.

The urban-rural divide appears to be growing as urban areas are considered more developed as compared to rural settlements across the world (Lu \& Chen, 2004). However, since the development varies across space and time, the comparative development often varies even among the urban areas. This can be explained by characterizing urban centers into primary and secondary cities. A primary city can be defined as an area that is disproportionately larger than any other urban hierarchy, and a leading city in its country or region (Goodall, 1987). Secondary cities, on the other hand, are defined based on population size, administrative extent, political, economic, and historical importance, and are smaller than the primary cities (B. Roberts \& Hohmann, 2014; Rondinelli, 1983). A few capital cities/metropolitans take away large amounts of budgets and resources, and the secondary cities, which are more in number, are left with fewer resources for development and maintenance. This trend shows government biasness towards certain cities with political concentration, and accumulation of wealth and resources, which eventually leads to concentrated infrastructure development in the urban centers. As a consequence, an upsurge in migration and population occurs in big cities which further increases the demand for resources. This inequality sometimes provokes public protests for fair and balanced development across regions. Although governing bodies try to enact policies to restrict inequalities, they usually fail to implement them on ground (B. H. Roberts, 2014).

Sustainable development has been a huge concern for Pakistan. The country ranked quite low in the Human Development Index (HDI), $147^{\text {th }}$ out of 188 countries (UNDP, 2015). In the province of Punjab (the largest in terms of population), rapid urbanization is taking place along with lopsided and haphazard development (Mayo, 2012). To tackle this, separate Development Authorities (DAs) were set up in the large cities of Lahore, Gujranwala, Rawalpindi, Multan and Faisalabad at different times under the Development Cities Act of 1976 (N. Ahmad \& Anjum, 2012). This Act allowed the government to grant powers to the DAs, in addition to Town Municipal Administrations (TMAs), to ensure planned urban growth through building control, and to provide infrastructure utilities in their respective areas. Moreover, the Punjab Local Government Ordinance of 2001 coined these five cities as 'city districts' and empowered the local administrations to take development initiatives (Government of Punjab, 2001). Although the goals 9 and 10 of global Sustainable Development Goals (SDGs) developed by the United Nations suggest developing resilient infrastructure and reducing inequality within countries (ICSU \& ISSC, 2015), the national development plans in Pakistan are oriented more towards infrastructure development than socioeconomic growth (Rana, 2014). This calls for an immediate evaluation of the development disparity to ascertain sustainable growth in the region.

The development progress can be studied using a wide variety of methods. Several spatial techniques like Global Moran's I, Geary's C and Local Indicators of Spatial Association (LISA) can be used to relate indicators with space that can help ascertain spatial inequalities (Duncan et al., 2012; Gutiérrez \& Delclòs, 2016). However, analyzing the spatial and temporal dynamics of infrastructure disparity at multiple spatial scales has not been carried out using these techniques. Indices, on the other hand, have been widely used and accepted - some of these have been explicitly formulated to measure inequalities and disparities (E. Ahmad, Ludlow, \& Mahmood, 1989; Hicks, 1997; Jamal \& Khan, 2007; Lee, Choi, \& Im, 2013). A commonly used measure is the Gross National Product/Gross Domestic Product (GNP/GDP) per capita for assessing the economic growth which helps in 
comparing effective development across regions. Other indices like HDI (Anand \& Sen, 1994), Gini inequality index (Dadashpoor, Rostami, \& Alizadeh, 2016; Yitzhaki, 1983), Theil Index (Lee et al., 2013; Theil, Raj, \& Koerts, 1992) and inequality adjusted HDI (Hicks, 1997) have also been used to compare inequalities. Quality of life has also been used to examine the development levels among settlements. Indices like physical quality of life index (Morris, 1979), World Health Organization's quality of life (The WHOQOL Group 1998) and index of well-being (Bobbitt, Green, Candura, \& Morgan, 2005) have been developed and employed. Regional inequalities and disparities have been measured in the local context by numerous authors on the basis of poverty and income (E. Ahmad et al., 1989), social wellbeing and quality of life (Bhatti, Tripathi, Nagai, \& Nitivattananon, 2016; Nawazul-Huda, Burke, \& Azam, 2011), education (Ghaus \& Pasha, 1996) and health (Midhet, 2004). Jamal and Khan (2007) developed HDI for each district of Pakistan to present a comparative picture of development at district level. However, limited studies have exclusively examined the infrastructure sector in the urban areas at a sub-district scale.

The selection of indicators/variables is the most critical part of defining an index (Williamson, 1965). The indicators data is normalized using data standardization techniques, whereas weighting techniques (objective and subjective) are employed to obtain the cumulative indices values (Khan, 2012; McCrea, Shyy, \& Stimson, 2006). The weights can be derived through opinion of the experts and/or previous empirical studies, and represent the relative importance of each factor based on its influence on development. Decision making techniques such as analytic hierarchy process (AHP) can be used for allocation of weights (Saaty, 1980). The composite index conjugates all the heterogeneous data into one reliable source of information. Various statistical tests, such as t-tests and coefficient of variances, can then be applied to observe and compare the differences among regions to measure the disparity. The two main objectives of this study are to: (1) develop an approach for examining spatiotemporal infrastructure development disparity at multiple scales; and (2) examine the spatiotemporal infrastructure development disparity in the city districts of Punjab province, Pakistan through the proposed approach.

\section{The approach for analyzing infrastructure development disparity}

An important aspect of the proposed approach is the integration of space and time to look at the infrastructure development disparity at multiple spatial scales. Three dimensions are therefore addressed: (1) multiple spatial scales - Tier-1 (smallest units and most detailed)... to Tier-N (largest single unit); (2) space - variation across space; and (3) time - variation across time. The framework of the proposed approach is presented in Figure 1.

The overall approach comprises three sequential phases; the first two primarily deal with the selection of spatial-temporal scales and development indicators, and computing the Infrastructure Development Index $(I D I)$, whereas the final phase involves performing different analyses to examine infrastructure development disparity at multiple spatial scales (Figure 1(a)). The dimension of space is presented as $x-y$ plane, whereas that of time as multiple spatial layers (Figure 1(b)). The multiple spatial scales refer to the smaller/detailed spatial units (Tier-1, Tier-2, ...) and larger/general spatial unit (Tier-N), where the smaller spatial units aggregate to form the larger spatial unit (Figure 1(c)). The quantity of spatial layers of time and spatial scales depends on the availability and level of detail of the data.

\section{Phase 1: Selection of spatial scales and time-series infrastructure development indicators}

The selection of spatial and temporal scales for examining infrastructure development disparity is quite relative, and depends on factors such as the indicators being used to assess the development and availability of data. The selection of indicators itself is linked to the local development context and availability of time-series data. Table 1 presents general guidelines that can be consulted while selecting the spatial and temporal scales, and the indicators. 
(a)

Phase 1: Selection of spatial scales and time-series infrastructure development indicators

Phase 2: Assessing the Infrastructure Development Index (IDI) values
Phase 3: Spatial and temporal analyses of $I D I$ to examine spatiotemporal disparity at multiple spatial scales

(b)

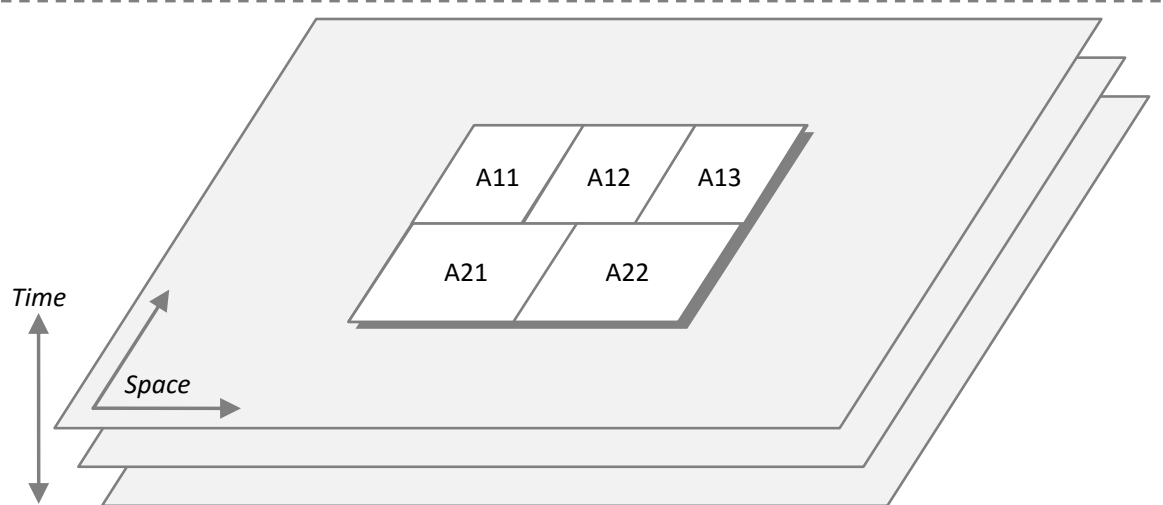

(c)

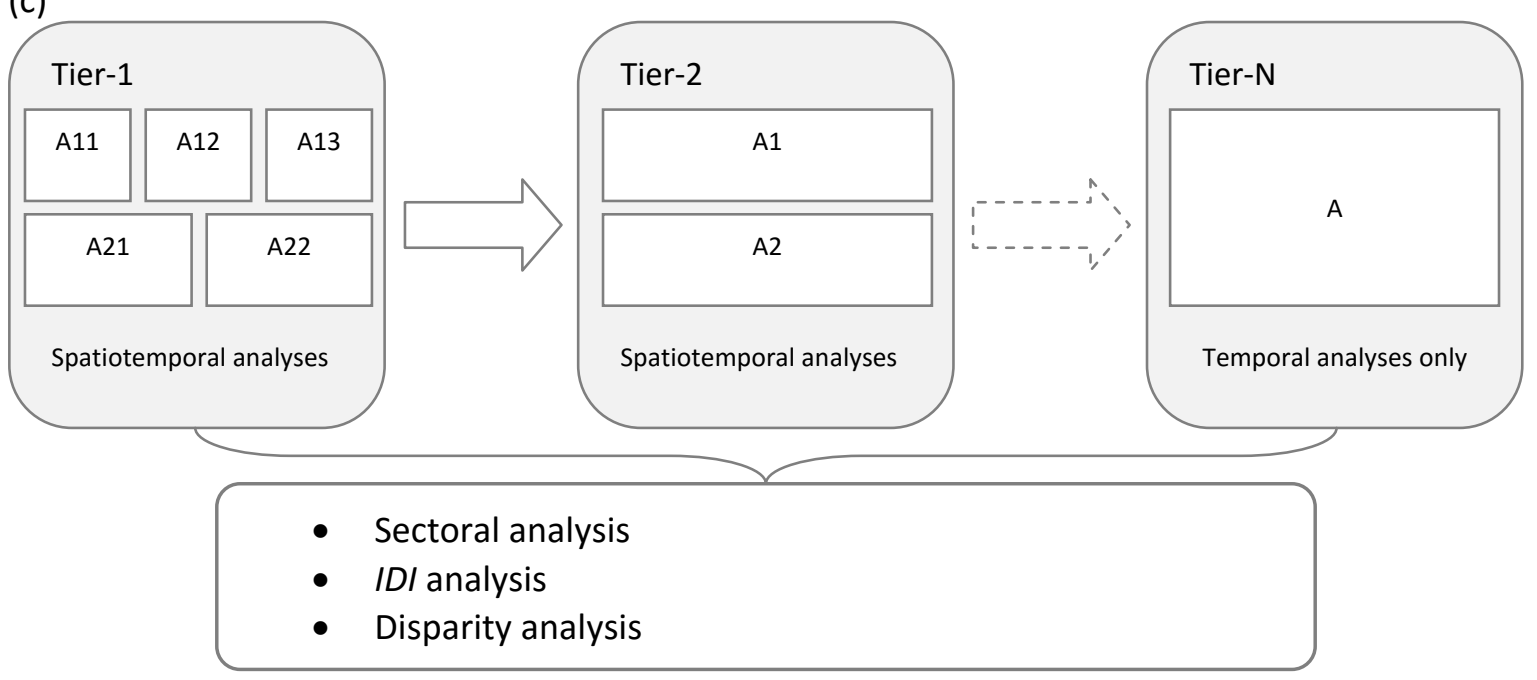

Figure 1. The approach for spatiotemporal analyses of infrastructure development disparity comprising (a) three sequential phases, (b) space-time dimension and (c) analyses at multiple spatial scales.

Table 1. General guidelines for selection of spatial scales and time-series infrastructure development indicators.

\begin{tabular}{lll}
\hline & Factors involved & Guidelines \\
\hline $\begin{array}{l}\text { Spatial and } \\
\text { temporal scales }\end{array}$ & $\begin{array}{l}\text { - Indicators selected } \\
\text { - Time-series data availability }\end{array}$ & $\begin{array}{l}\text { All spatial scales need to be consistent with the } \\
\text { study area extent. }\end{array}$ \\
$\begin{array}{l}\text { Infrastructure } \\
\text { development } \\
\text { indicators }\end{array}$ & $\begin{array}{l}\text { - Study area } \\
\text { Time-series data availability }\end{array}$ & $\begin{array}{l}\text { The data related to indicators should ideally be } \\
\text { at the spatial scale representing highest possible } \\
\text { detail (Tier-1 scale). }\end{array}$ \\
\hline
\end{tabular}




\section{Phase 2: Assessing the IDI values}

The next step involves processing the data through three sequential steps: (1) data normalization standardizing all the data to a common quantitative scale; (2) indicator weights computation assessing the relative importance of each indicator; and (3) IDI computation - application of weights to the normalized data.

Data standardization is quite important as the quantitative scale and data sources might not be the same for all the datasets. There are a variety of methods for normalizing quantitative data such as Transformed Value (TV), z-score data standardization and uncorrected standard deviation (Gan, Ma, $\& W u, 2007)$. The selection of the method is subjective and the effect of different established normalization methods on overall IDI values is negligible. The TV normalization method is suggested in the proposed approach, which is computed by Equation 1 (Gan et al., 2007).

$$
T V=\frac{x_{i j}-x_{i}(\min )}{x(\max )-x(\min )}
$$

Where $T V$ is the transformed value of the indicator, $x_{i j}$ is the value of $\mathrm{i}^{\text {th }}$ indicator in $\mathrm{j}^{\text {th }}$ unit of Tier- 1 scale, $x(\min )$ is the minimum value in the $\mathrm{i}^{\text {th }}$ indicator and $x(\max )$ is the maximum value in the $\mathrm{i}^{\text {th }}$ indicator. The proposed approach suggests using weighted sum method for aggregating the transformed values (TVS) to obtain IDI value; it takes care of the relative importance of each indicator (Triantaphyllou, 2013). The indicator weights, however, could not be pre-determined as the relative significance of each indicator is not the same in each study area. Obtaining the local field experts' opinion in this regard is thus recommended, which can be translated into a pairwise comparison matrix for application of AHP weighting method (Saaty, 1980). This matrix helps assessing the consistency of the experts' judgements through consistency ratio $(C R)$ computed using Equation 2.

$$
C R=\frac{C I}{R I}
$$

Where $R I$ is the random index which is a constant and its value depends on the number of indicators being compared, and $\mathrm{Cl}$ is the consistency index computed by Equation 3 (Saaty, 1980).

$$
C I=\frac{\lambda-n}{n-1}
$$

Where $\lambda$ is the averaged consistency vector value computed by means of pairwise comparison matrix, and $n$ is the number of indicators being compared. The $C R$ value higher than 0.1 implies inconsistent judgements and in such a situation, the pairwise comparison matrix should be revisited (Saaty, 1980). Once the required consistency in the judgments is achieved $(C R \leq 0.1)$, the indicator weights can be computed by the $\lambda$ matrix.

After obtaining the indicator weights through AHP, the IDI values can be computed by applying the weighted sum method through Equation 4. The proposed approach suggests computing the IDI value of each unit of Tier- 1 scale for all the selected time-series for further analyses.

$$
I D I=\sum W_{n} T V_{n}
$$

Where $I D I$ is the infrastructure development index, $W_{n}$ and $T V_{n}$ are the weight and transformed value, respectively, of the $\mathrm{n}^{\text {th }}$ indicator. 


\section{Phase 3: Spatial and temporal analyses of IDI to examine spatiotemporal disparity at multiple spatial scales}

A variety of analyses can be performed on the data prepared in Phase 2. An important point, however, is that some analyses can be performed in both spatial and temporal dimensions, whereas some can examine only the temporal aspect; it depends on the spatial scale (Tier) under observation. Considering all the data is prepared at Tier-1 scale for all the time-series selected in Phase 1 , the proposed approach guides that both spatial and temporal analyses can be performed at all spatial scales, except Tier- $\mathrm{N}$ at which only temporal analyses can be performed. Spatial variations cannot be examined at Tier- $\mathrm{N}$ scale as it is composed of only one unit (Figure 1(c)).

An important step is the transformation of data from one spatial scale to another. For instance, the data prepared at Tier-1 scale needs to be converted to Tier-2 scale in order to perform analyses at the later scale. It is done by computing the mean value of the data. Consider a case where five units $(a 1, a 2, a 3, b 1, b 2)$ at Tier-1 scale and two units $(a, b)$ at Tier-2 scale comprise the single unit study area (Tier-3 scale), where $a$ is composed of $a 1, a 2$ and $a 3$ and $b$ is composed of $b 1$ and $b 2$, and the study area is composed of $a$ and $b$. Assuming $v$ is some data value of a unit, the data transformation from Tier-1 scale to Tier-2 scale is done by $a v=(a 1 v+a 2 v+a 3 v) / 3$ and $b v=(b 1 v+b 2 v) / 2$. Similarly, the data value $v$ at Tier-3 scale (study area) is computed by $(a v+b v) / 2$.

The analyses can be broadly categorized as: (1) sectoral; (2) IDI; and (3) disparity. The sectoral analysis assesses the spatial and temporal variations in each indicator which helps in understanding the development disparity with respect to different development sectors. Since each indicator is individually evaluated in this analysis, the results could be useful to judge the extent of success or failure of related policy programs. The statistical operation of coefficient of variance $\left(C_{v}\right)$, which measures the extent of variability in relation to the mean of the data, is applied to the $T V$ of each indicator. The $C_{v}$ is the ratio of standard deviation $(\sigma)$ to the mean $(\mu)$ of the data (Equation 5 ), and is often expressed as a percentage (Everitt, 2003).

$$
C_{v}=\frac{\sigma}{\mu} \times 100
$$

The $I D I$ analysis provides an overview of the infrastructure development at different spatial scales over time. The IDI values are computed at Tier-1 scale using Equation 4; further processing is carried out to obtain $I D I$ values at other spatial scales (discussed above). The temporal development trend can be categorized as declining (development deteriorating over time), constant (no change in development over time), progressive (development improving over time) or fluctuating (variable trend in development over time). This analysis provides an overview of the infrastructure development disparity over space and time.

The infrastructure development disparity is also quantified through statistical tests. The proposed approach suggests using the $C_{v}$ and paired sample t-test. The $C_{v}$ is computed by Equation 5 using the $I D I$ data, which indicates the spatiotemporal infrastructure development variability within the study area. The paired sample t-test, on the other hand, provides the infrastructure development trend significance between two time periods. Negative $t$ value indicates that the later time period exhibits improved development compared to the initial time, and vice versa. This test assists understanding the infrastructure development dynamics during different time periods at variable spatial scales. 


\section{Application of the proposed approach}

\subsection{Study area}

The approach discussed in Section 2 was applied to a case study area, the five city districts of the province of Punjab, Pakistan namely Faisalabad, Gujranwala, Lahore, Multan and Rawalpindi. The population of the province is around 101 million (2015 estimate), where around 9.5 million reside in the provincial capital Lahore (largest city of the province) (Punjab Bureau of Statistics, 2015). Total 39 towns comprise the selected city districts (the hierarchy of administrative units in Pakistan, from largest to smallest, is: country, province, division, district/city district, tehsil/town and union council). Since population size is the determining factor in defining primary and secondary cities (B. H. Roberts, 2014; B. Roberts \& Hohmann, 2014), and the future estimates suggest a significant rise in built-up areas in Lahore (Bhatti, Tripathi, Nitivattananon, Rana, \& Mozumder, 2015), the provincial capital was categorized as the primary city and the rest were classified as secondary cities in this study. Administratively, however, all the city districts are at the same level in the hierarchy. The map of the study area is shown in Figure 2, whereas some population and administrative statistics of the five city districts are shown in Table 2.

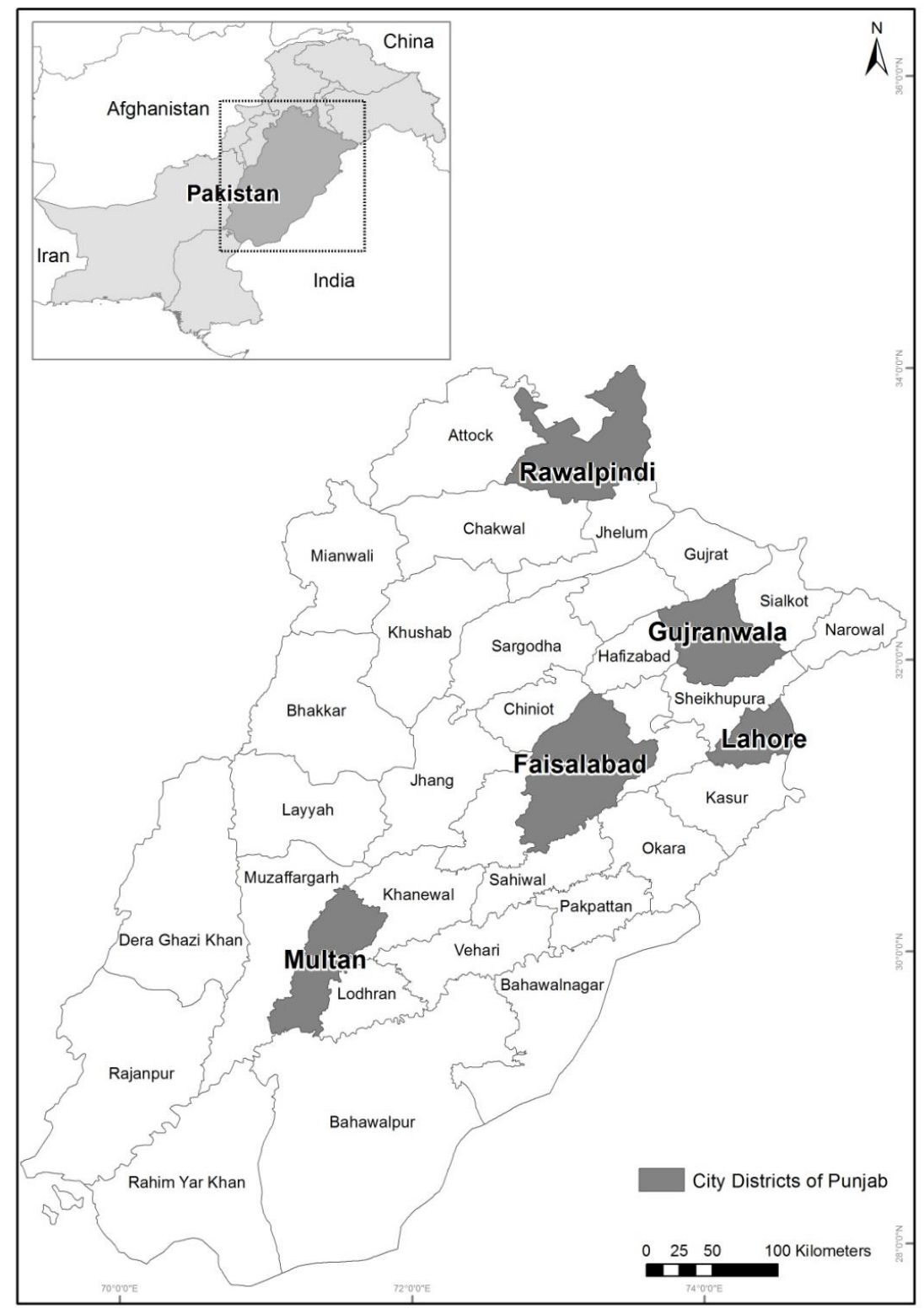

Figure 2. Map of the study area, the city districts of Punjab province, Pakistan. 
Table 2. Population (2015) and administrative statistics of the city districts of Punjab province, Pakistan.

\begin{tabular}{lllll}
\hline $\begin{array}{l}\text { City } \\
\text { Category }\end{array}$ & City District & $\begin{array}{l}\text { Population } \\
\text { (thousand persons) }\end{array}$ & $\begin{array}{l}\text { Urban population } \\
\text { proportion (\%) }\end{array}$ & Number of Towns \\
\hline Primary & Lahore & 9,447 & 82.2 & 10 \\
& & & & 8 \\
& Faisalabad & 7,358 & 42.7 & $7^{*}$ \\
Secondary & Gujranwala & 4,788 & 50.9 & $6^{*}$ \\
& Multan & 4,332 & 42.1 & $8^{*}$ \\
& Rawalpindi & 4,691 & 55.8 &
\end{tabular}

Source: Punjab Bureau of Statistics (2015).

* Excluding Army Cantonments

\subsection{Selection of spatial scales and time-series infrastructure development indicators}

Three spatial scales were considered in this study; town (Tier-1), city district (Tier-2) and province (Tier-3). It should be noted that the province scale in this paper refers to the aggregation of data of only the five city districts, and does not include rest of the Punjab. A total five indicators (Table 3) were used to examine the development status in the towns with respect to policy and programs initiated during three time periods, 2002, 2007 and 2012. The selection of spatial and temporal scales, and the indicators was based primarily on the review of literature and availability of reliable data. The selected development sectors (indicators) also reflected the Millennium Development Goals (MDGs) partially, which aim at decreasing inequalities and poverty in urban areas through providing access to safe drinking water, improved sanitation and schools.

Table 3. Development indicators selected and their description.

\begin{tabular}{ll}
\hline Indicator notation & Description \\
\hline$X_{1}$ & Percentage of households having access to secondary school (within 5km) \\
$X_{2}$ & Percentage of households having access to electricity \\
$X_{3}$ & Percentage of households using gas as cooking fuel \\
$X_{4}$ & Percentage of households having access to improved water sources \\
$X_{5}$ & Percentage of households having access to improved sanitation \\
\hline
\end{tabular}

The data of the indicators was extracted from the official reports on Multiple Indicator Cluster Survey (MICS) published by the Bureau of Statistics, Planning and Development Department, Government of the Punjab (Punjab Bureau of Statistics, 2004, 2009, 2011). The city district scale (Tier-2) data is presented in Table 4. It is important to note that the indicators data of 2007 and 2012 was available at town scale (Tier-1), whereas that of 2002 was available only at the city district scale (Tier-2).

\subsection{Assessing the Infrastructure Development Index (IDI) values}

The indicators data of 2007 and 2012 was normalized to a scale of 0-1 using Equation 1 to obtain the $T V$ of each indicator in each town, whereas that of 2002 was obtained for each city district. The indicator weights were computed using the AHP method where the relative importance of each IDI indicator was determined using the opinion of seven local field experts from: Town Planning Wing and Metropolitan Wing of Lahore Development Authority; Rawal Town Municipal Administration; Urban Unit of Planning and Development Department; and City and Regional Planning Department of University of Engineering and Technology - an online survey was conducted for this purpose. The $C R$ value of $0.08(C l=0.09 ; R I=1.12)$ computed through Equation 2 indicated that the experts' judgments were consistent, and the indicator weights were reliable. The weighted sum method (Equation 4) was subsequently applied to the TVs to compute the IDI value of each town (2007 and 2012) and each city district (2002, 2007 and 2012). 
Table 4. The data of development indicators at city district scale (Tier-2).

\begin{tabular}{lllllll}
\hline Indicator* & Year & Lahore & Faisalabad & Gujranwala & Multan & Rawalpindi \\
\hline \multirow{3}{*}{$X_{1}$} & 2002 & 99.50 & 97.00 & 99.00 & 92.00 & 98.00 \\
& $2007^{* *}$ & 93.41 & 98.64 & 98.09 & 91.73 & 95.23 \\
& $2012^{* *}$ & 95.47 & 99.76 & 99.20 & 92.35 & 95.79 \\
& & & & & & \\
$X_{2}$ & 2002 & 99.00 & 96.00 & 99.00 & 80.00 & 99.00 \\
& $2007^{* *}$ & 99.70 & 98.31 & 99.74 & 90.23 & 95.63 \\
& $2012^{* *}$ & 99.75 & 99.36 & 99.70 & 96.42 & 98.01 \\
& & & & & & \\
$X_{3}$ & 2002 & 72.00 & 30.00 & 38.00 & 37.00 & 46.00 \\
& $2007^{* *}$ & 81.29 & 35.91 & 55.31 & 34.87 & 36.33 \\
& $2012^{* *}$ & 83.69 & 51.86 & 60.60 & 54.62 & 43.59 \\
$X_{4}$ & 2002 & 99.00 & 80.00 & 100.00 & 99.00 & 89.00 \\
& $2007^{* *}$ & 98.61 & 91.21 & 99.40 & 99.73 & 87.43 \\
& $2012^{* *}$ & 99.90 & 85.86 & 99.98 & 99.72 & 87.60 \\
& & & & & & \\
$X_{5}$ & 2002 & 94.40 & 75.00 & 84.00 & 64.00 & 70.00 \\
& $2007^{* *}$ & 95.39 & 81.55 & 94.84 & 65.75 & 77.09 \\
\hline
\end{tabular}

* The notations used for IDI indicators are described in Table 3.

** Town scale (Tier-1) data aggregated to present city district scale (Tier-2) data.

\subsection{Spatial and temporal analyses of $I D I$ to examine spatiotemporal disparity at multiple spatial} scales

The sectoral, IDI and disparity analyses were performed to examine the infrastructure development disparity at multiple scales; the development inequality between the primary and secondary cities was also examined. Some analyses were performed in both spatial and temporal dimensions whereas only temporal aspect was examined in others (Table 5). The description of the analyses mentioned in Table 5 is given in Section 2.

Table 5. The different analyses with respect to spatial scale, spatial and temporal dimensions.

\begin{tabular}{|c|c|c|c|c|}
\hline Analysis Category & Analysis & Spatial Scale & $\begin{array}{l}\text { Spatial } \\
\text { Variability* }\end{array}$ & $\begin{array}{l}\text { Temporal } \\
\text { Variability* }\end{array}$ \\
\hline \multirow{2}{*}{ Sectoral analysis } & \multirow{2}{*}{$\begin{array}{l}\text { Coefficient of } \\
\text { variance }\end{array}$} & City district (Tier-2) & $\checkmark$ & $\checkmark$ \\
\hline & & Province (Tier-3) & $x$ & $\checkmark$ \\
\hline \multirow{4}{*}{$\begin{array}{l}\text { Infrastructure } \\
\text { Development } \\
\text { Index (IDI) analysis }\end{array}$} & \multirow{4}{*}{$\begin{array}{l}\text { Spatiotemporal } \\
\text { trend }\end{array}$} & Town (Tier-1) & $\checkmark$ & $\checkmark$ \\
\hline & & City district (Tier-2) & $\checkmark$ & $\checkmark$ \\
\hline & & Province (Tier-3) & $x$ & $\checkmark$ \\
\hline & & & & $\checkmark$ \\
\hline \multirow{4}{*}{ Disparity analysis } & \multirow{4}{*}{$\begin{array}{l}\text { Coefficient of } \\
\text { variance } \\
\text { Paired sample t- } \\
\text { test }\end{array}$} & City aistrict (lier-<) & $\checkmark$ & $\checkmark$ \\
\hline & & Province (Tier-3) & $x$ & $\checkmark$ \\
\hline & & City district (Tier-2) & $\checkmark$ & $\checkmark$ \\
\hline & & Province (Tier-3) & $x$ & $\checkmark$ \\
\hline
\end{tabular}




\section{Results and discussion}

\subsection{The indicator weights and IDI}

The results indicated that the highest importance, in the opinion of local field experts, was that of the provision of improved water sources followed by improved sanitation facilities (Figure 3). This choice could be attributed to the rather poor situation of water and sanitation in the country which has prompted the national and international development focus (MDGs) towards these necessities. Provision of electricity and gas followed in the chart. Interestingly, the factor of having access to secondary school within 5 kilometers of the household was perceived as the least important among the five indicators. It can be inferred that the local conditions do not allow for considering access to educational facilities as a much important factor towards infrastructure development, compared to the other indicators under observation.

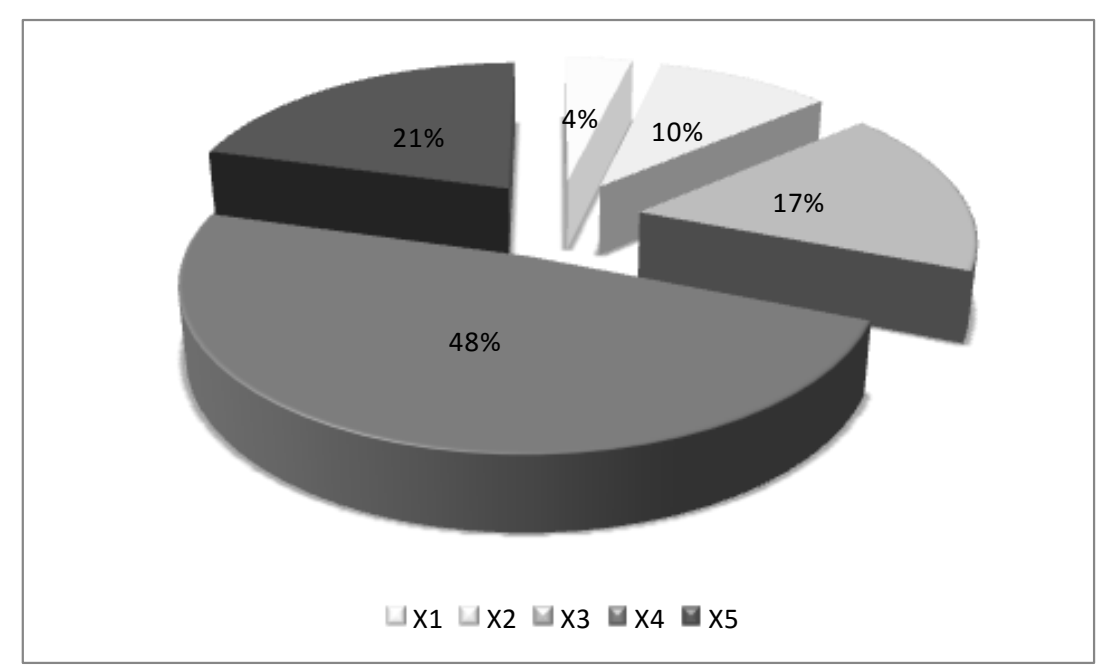

Figure 3. Weights of IDI indicators determined by local field experts and computed through AHP.

* The notations used for IDI indicators are described in Table 3.

\subsection{Sectoral analysis}

At city district scale (Tier-2), a decrease in variance in the five development sectors was observed in general between 2007 and 2012 in majority of the cities; however, the spatial variability of the indicators was quite evident during both times (Figure 4). The city district Lahore was significantly different from the other city districts in terms of having access to secondary schools during both 2007 and 2012; the spatial variability was quite high compared to that in other city districts (Figure 4(a)). This characteristic can be attributed to the population size and density of the provincial capital which are considerably higher than other city districts. A $C_{v}$ value of just around $5 \%$ suggests that despite being different from other cities, the access to high schools in Lahore is still quite reasonable. The spatial variability in this indicator was even less in the rest of the city districts suggesting spatial consistency and reasonable level of access to education in all the city districts of Punjab; a trend of improvement was observed during 2007 and 2012.

Highest spatial variance was observed in city districts Multan and Rawalpindi in terms of having access to electricity in 2007; however, this variability reduced significantly from around $9 \%$ to $3 \%$ in Multan between 2007 and 2012, whereas that in Rawalpindi reduced from around 7\% to 4\% during this period (Figure 4(b)). Reduction in spatial variability in this sector was also observed in city district Faisalabad during this period, whereas city districts Lahore and Gujranwala remained almost consistent and exhibited lowest variance. The results indicate that the provision of electricity is quite uniform spatially across city districts Lahore, Gujranwala and Faisalabad, whereas there is room for improvement in this sector in city districts Rawalpindi and Multan. 

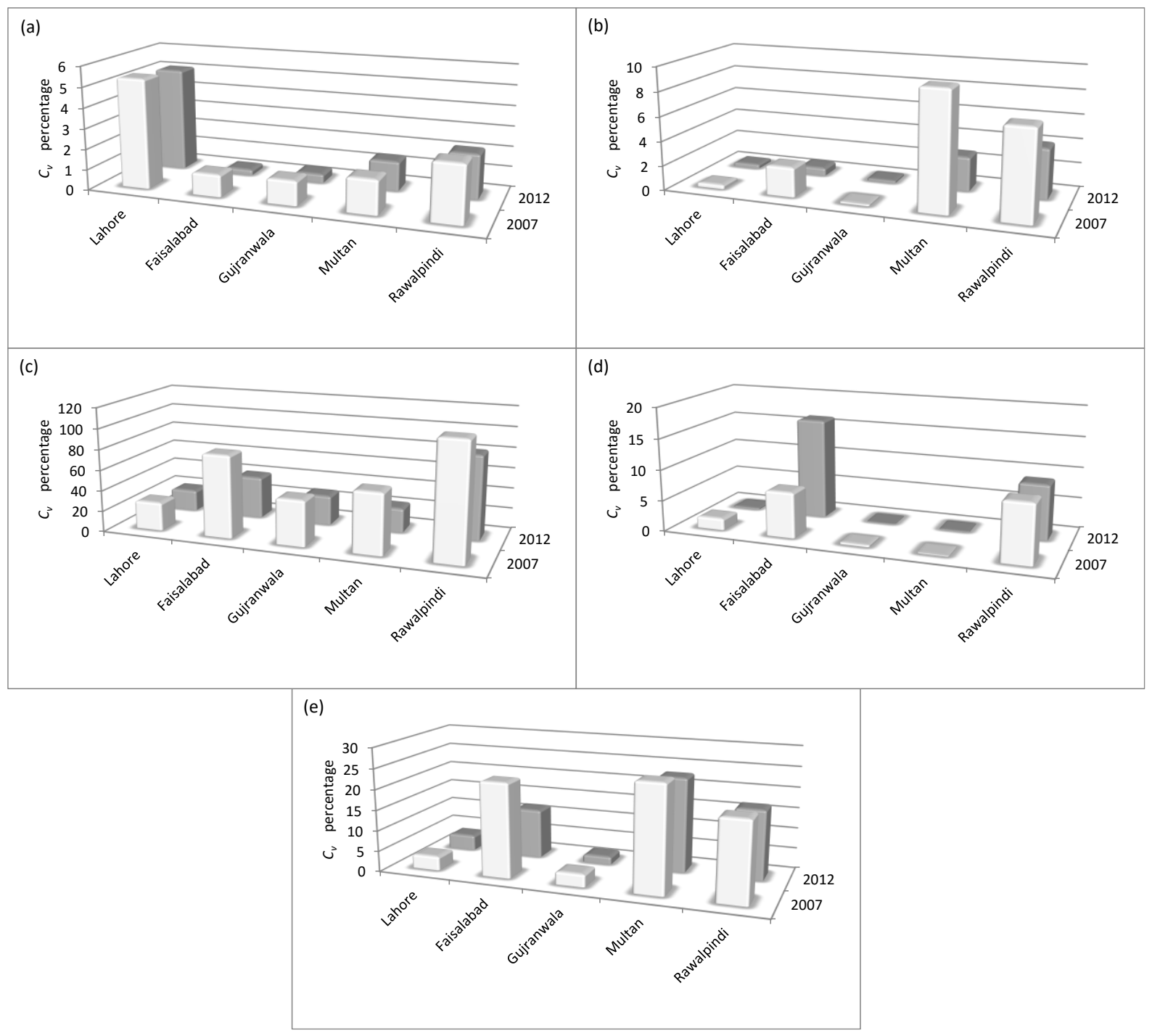

Figure 4. Spatiotemporal variability in percentage of households (a) having access to secondary school (within $5 \mathrm{~km}$ ), (b) having access to electricity, (c) using gas as cooking fuel, (d) having access to improved water sources and (e) having access to improved sanitation in 2007 and 2012 at city district scale (Tier-2) in Punjab, Pakistan.

Significant spatial variance was observed (highest among all five infrastructure sectors considered) in the provision of gas as a cooking fuel in all the city districts, though a trend of reduction was observed between 2007 and 2012 (Figure 4(c)). The highest was in city district Rawalpindi, around $111 \%$ in 2007 , which reduced to around $82 \%$ in 2012 . The reason was the lack of provision of this facility to the Kotli Sattian town in Rawalpindi in 2007, which gradually improved by 2012 . The second highest variance was observed in city district Faisalabad, whereas the least was found in city district Lahore. The results indicate that the infrastructure for provision of gas as a cooking fuel to the households in the city districts of Punjab is not spatially uniform; although the situation has gradually improved, further attention is needed in the study area.

All the city districts, except Faisalabad and Rawalpindi exhibited very low spatial variance in provision of improved water resources in both 2007 and 2012 (Figure 4(d)). Interestingly, the variance increased in Faisalabad from around 7\% to 16\% during 2007 and 2012, which could be attributed to the expansion of built-up areas to the extents where the access to improved water sources is still limited. Moreover, the quality of water in this area is not good in general; improper dumping of industrial waste is considered as the primary source of contamination (Hanif, Nadeem, 
Rashid, \& Zafar, 2005). Although improvement is evident in four out of five city districts between 2007 and 2012, immediate measures are needed in city district Faisalabad to provide access to this commodity to the expanding built-up areas. In city district Rawalpindi, the spatial variance in this sector can be reduced by stretching the associated infrastructure to the remote areas.

The spatial variance in access to improved sanitation facilities reduced in all the city districts, except Lahore, during 2007 and 2012 (Figure 4(e)). Although the variance in city district Lahore is the second lowest among the five, the slight increase in $C_{v}$ from around $3.4 \%$ to $3.7 \%$ during 2007 and 2012 indicates that appropriate sanitation infrastructure has not been developed/extended to cope with the escalating population and built-up areas in the provincial capital. The lowest variance was found in city district Gujranwala indicating a uniform distribution of sanitation infrastructure across its towns, whereas city districts Multan, Rawalpindi and Faisalabad exhibited comparatively higher spatial variance in this sector. These findings prompt the need to improve the sanitation infrastructure in the study area, especially in city districts Multan, Rawalpindi, Faisalabad and Lahore.

The spatiotemporal variation in infrastructure development sectors was quite dynamic when observed at the province scale (Tier-3) in the city districts of Punjab; no obvious trend was observed in majority of the sectors except the access to electricity whose spatial variability consistently decreased during 2002 and 2012 (Figure 5). The highest variability was observed in the provision of gas as a cooking fuel, while the least was noticed in access to electricity. Examining the development sectors in most recent time (2012), it can be deduced that there is a need to improve and extend the infrastructure related to provision of gas, sanitation and water to meet the growing demands resulting from population rise and expansion of built-up areas in the city districts of Punjab.

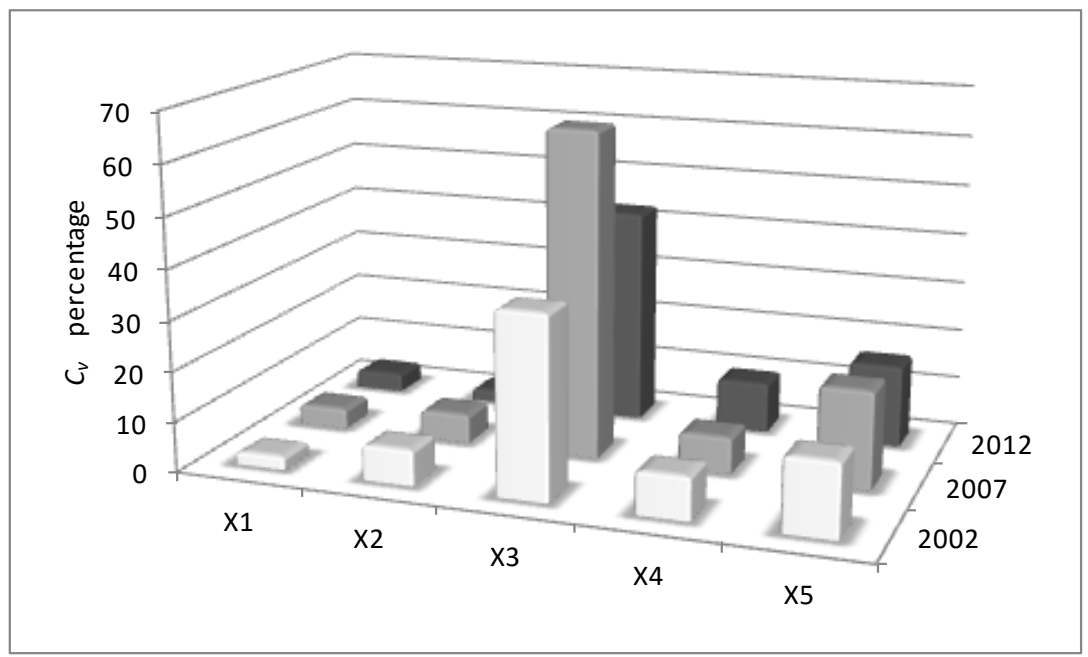

Figure 5. Temporal variability in development sectors at province scale (Tier-3) in city districts of Punjab, Pakistan during 2002, 2007 and 2012.

* The notations used for IDI indicators are described in Table 3.

\subsection{IDI analysis}

The spatial variability of $I D I$ in the towns of the five city districts is shown in Figures 6 and 7 for 2007 and 2012, respectively, whereas the spatiotemporal dynamics of $I D I$ during this period at town scale (Tier-1) are shown in Figure 8. All towns in city district Lahore indicated an improvement in infrastructure development between 2007 and 2012 (Figure 8(a)). Data Ganj Bukhsh, Gulberg, Ravi, Samanabad and Shalimar towns exhibited near to ideal IDI values in 2012 (Figure 7(a)), indicating good levels of development. The situation in Faisalabad was not quite reasonable where a few towns indicated a negative progress in terms of infrastructure development during 2007 and 2012 (Figure $8(b))$. These included Iqbal, Lyallpur and Madina towns which interestingly are not far from the city 
center (Figures $6(\mathrm{~b})$ and $7(\mathrm{~b})$ ). This finding indicates improper or lack of management/maintenance of the existing infrastructure in these towns. The state of infrastructure development improved in Chak Jhumra, Jaranwala, Summundari and Tandlianwala towns during 2007 and 2012, the majority of which are spatially farther from the city center. The overall situation of infrastructure development in city district Gujranwala was quite good, the second best among the five city districts in the study area (Figure 8(c)). However, unlike city district Lahore, a few towns located at the outer extents of Gujranwala indicated a slightly declining trend during 2007 and 2012 (Figures 6(c) and $7(c))$. This could be attributed to the expansion of built-up areas to the locations where the infrastructure is yet to be improved. Despite this, the level of infrastructure development in these towns (least developed in city district Gujranwala) was still better than the majority of towns in Multan and Rawalpindi city districts in 2012 (Figure 8).
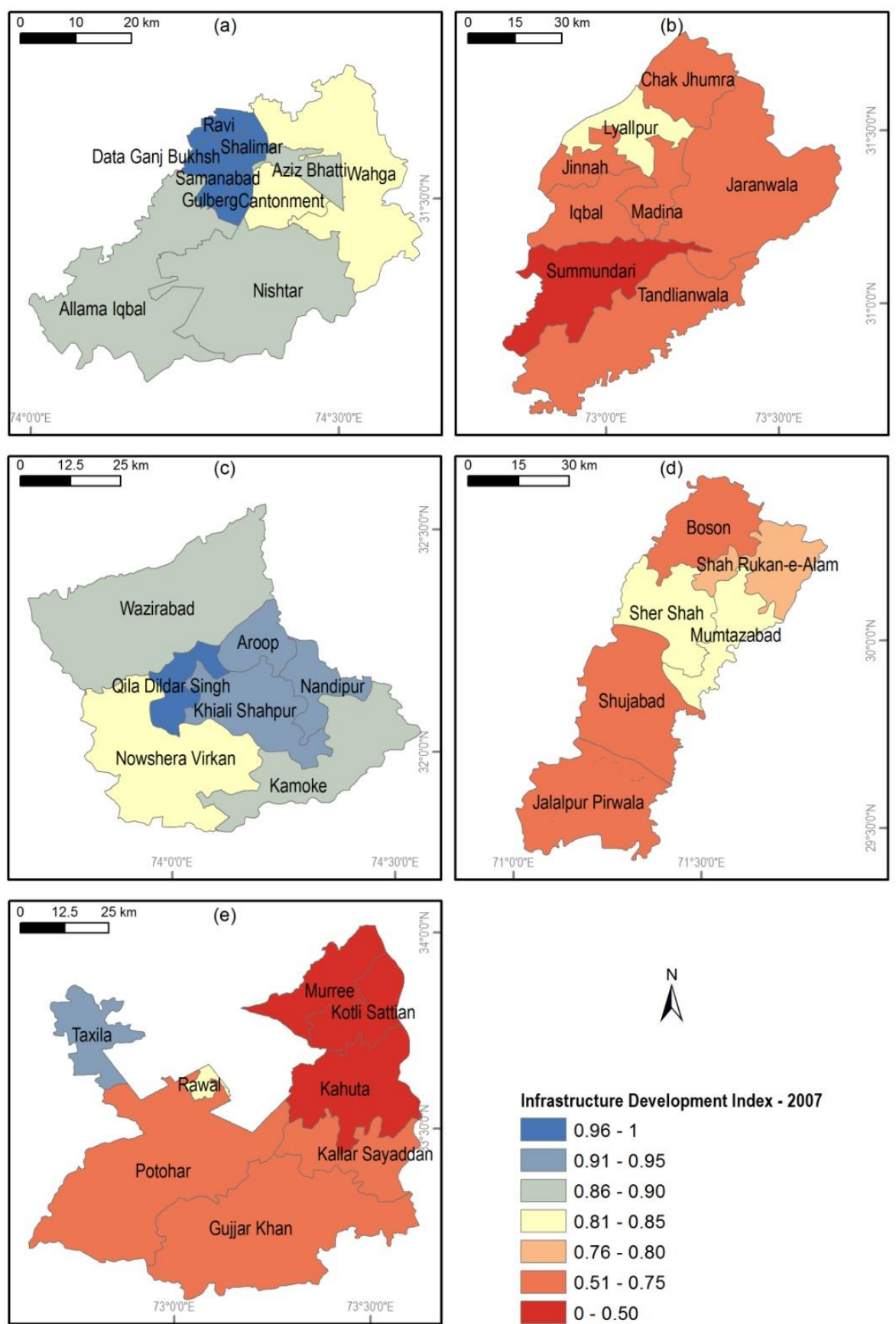

Infrastructure Development Index - 2007

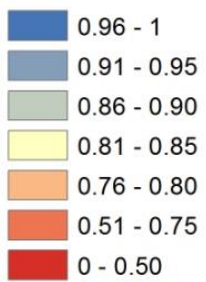

Figure 6. Spatial dynamics of IDI in the towns of city district (a) Lahore, (b) Faisalabad, (c) Gujranwala, (d) Multan and (e) Rawalpindi in 2007. 

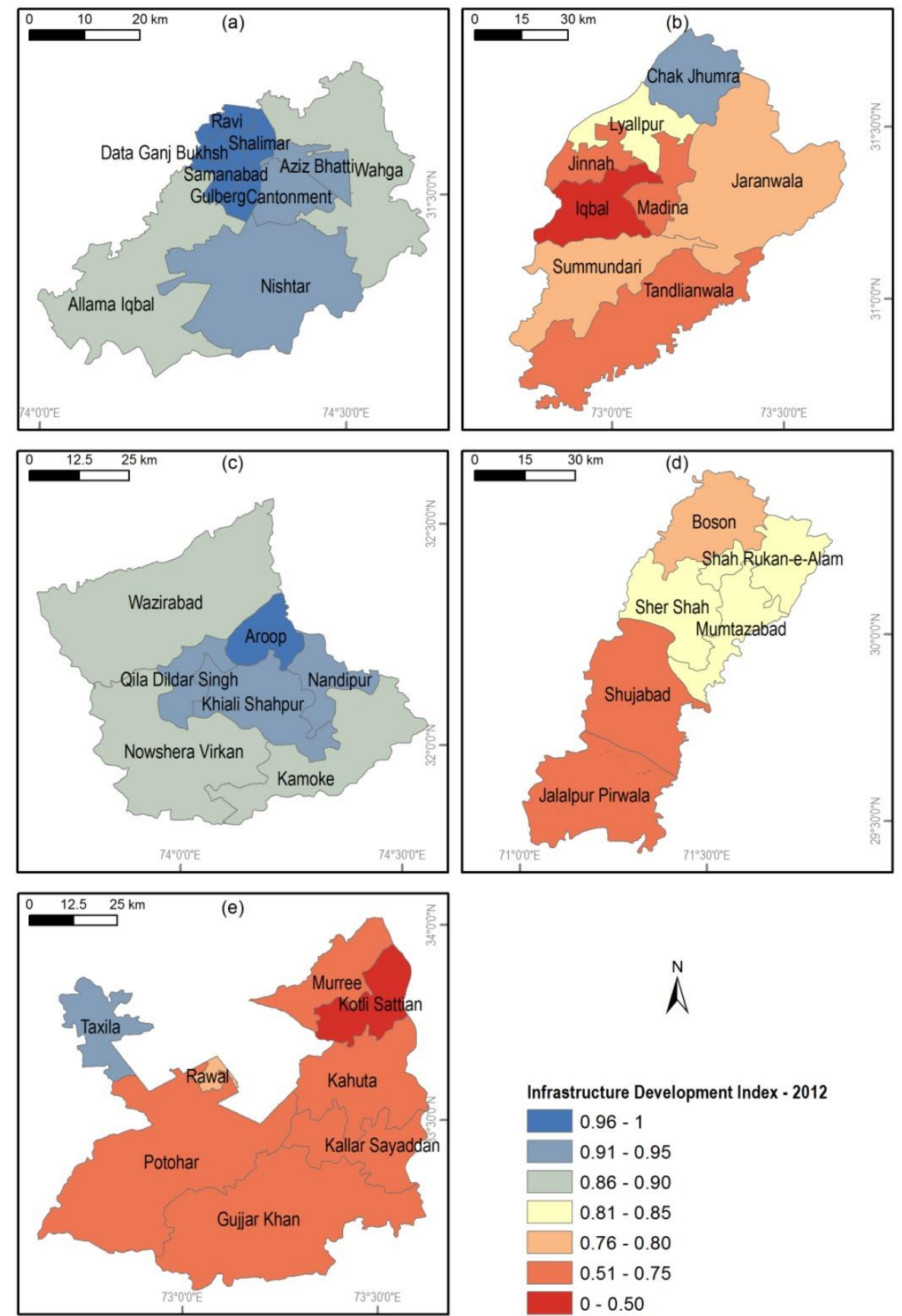

Figure 7. Spatial dynamics of $I D I$ in the towns of city district (a) Lahore, (b) Faisalabad, (c) Gujranwala, (d) Multan and (e) Rawalpindi in 2012.

An average infrastructure development situation was observed in the city district Multan where a few towns indicated a negative progress during 2007 and 2012 (Figure 8(d)). The overall level of development in this area is not quite good as compared to Lahore or Gujranwala. The least development was observed in the towns (Jalalpur Pirwala and Shujabad) far from the city center (Figures 6(d) and $7(d)$ ). These results suggest that Multan as a whole requires measures to improve the infrastructure development; the towns in the outskirts particularly require additional support in this regard. Although seven out of the eight towns in city district Rawalpindi indicated improvement during 2007 and 2012, the overall development state was not quite good (Figure 8(e)). In fact, Kotli Sattian was the least developed among all the towns in the study area during both the times. Taxila 
was the most developed town during both 2007 and 2012 (Figures 6(e) and 7(e)). The only town showing a declining development trend during 2007 and 2012 was the Rawal town (core of the city district); this points to the inadequacy of existing infrastructure towards fulfilling the requirements of rising population in this central town.
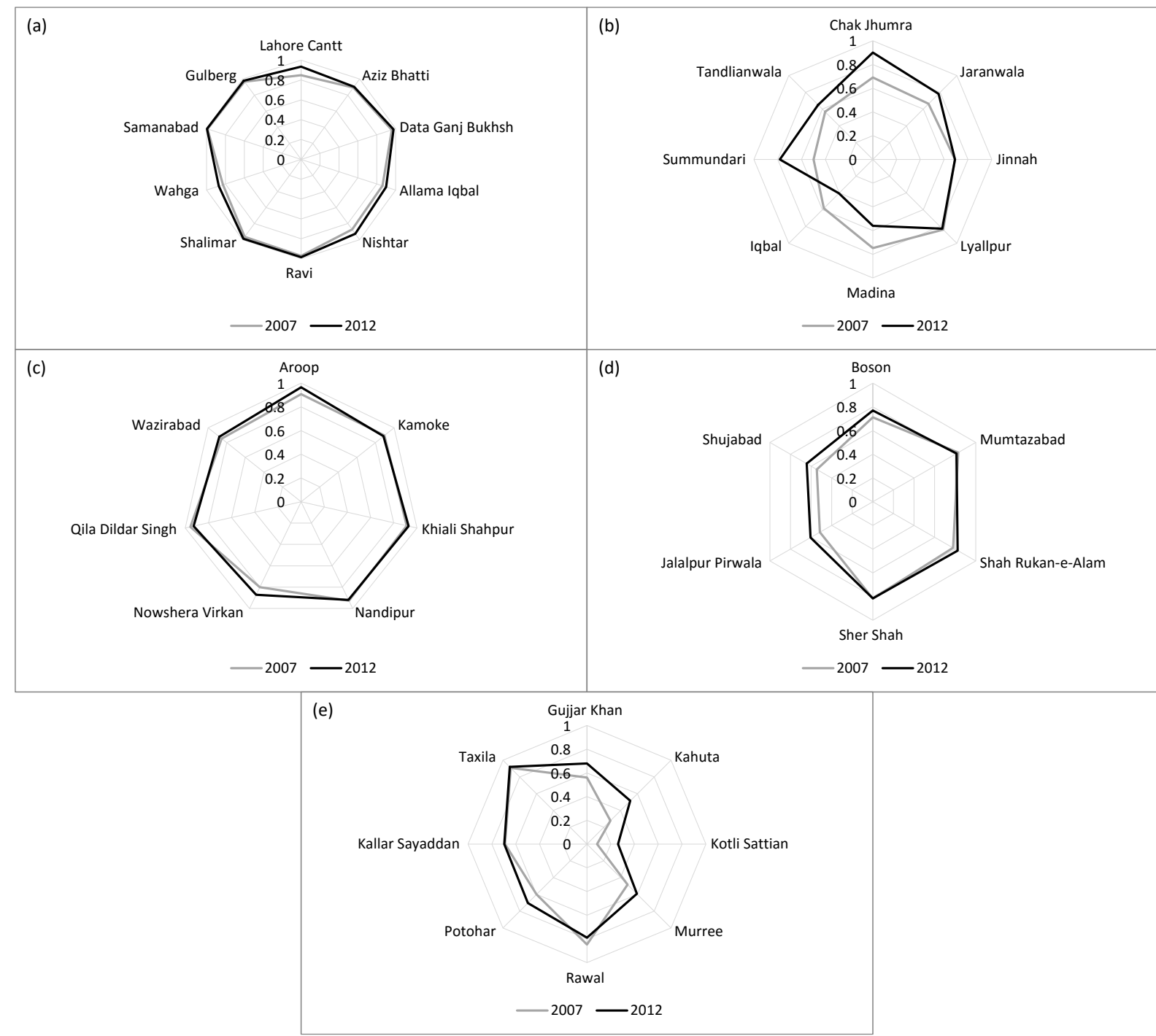

Figure 8. Spatiotemporal variability in IDI in city district (a) Lahore, (b) Faisalabad, (c) Gujranwala, (d) Multan and (e) Rawalpindi during 2007 and 2012 at town scale (Tier-1) in Punjab, Pakistan.

The infrastructure development trend during 2007 and 2012 was categorized as progressive, constant or declining in the five city districts using temporal IDI values of the respective towns (Figure 9). The city district Lahore exhibited a progressive development trend in all of its towns and clearly stood out compared to the other city districts. Although the infrastructure development was quite low in city district Rawalpindi (Figure $8(\mathrm{e})$ ), the progressive development trend in majority of its towns ( 7 of 8 towns progressed) indicated that the things are moving in a positive direction. The lowest development trend was observed in city district Gujranwala ( 3 of 7 towns declined); however, the overall situation appears fine as the Tier-1 results show high levels of infrastructure development in its towns (Figure 8(c)). On the contrary, the situation in city district Faisalabad is not good both in terms of Tier-1 IDI values (Figure $8($ b)) as well as the infrastructure development trend (3 of 8 towns declined) (Figure 9). These results point to the lack/deficiency of measures taken to sustain or improve the infrastructure development in city district Faisalabad during 2007 and 2012. 


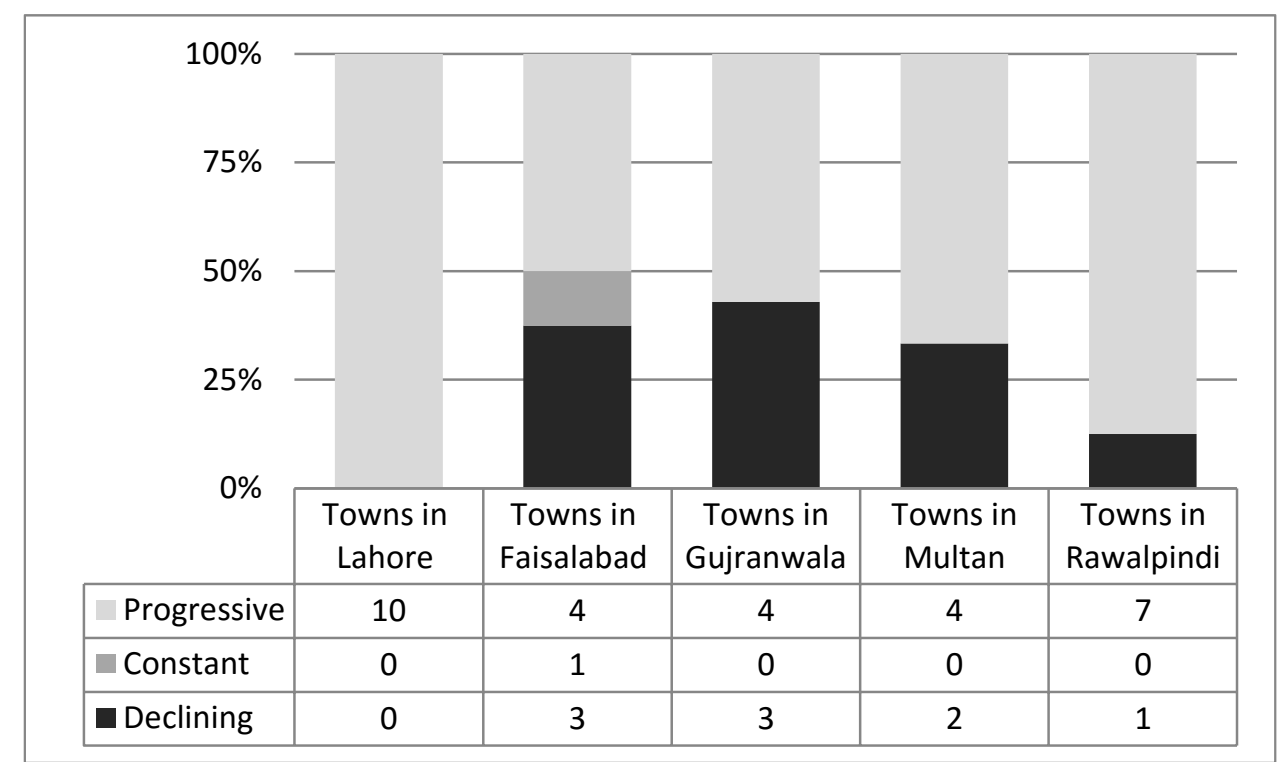

Figure 9. Temporal infrastructure development trend (between 2007 and 2012) in the towns of the city districts of Punjab, Pakistan.

The infrastructure development appeared quite positive when examined at the city district scale (Tier-2); all the city districts exhibited a progressive trend during 2002-2012 (Figure 10). Major improvements were seen in city districts Faisalabad, Multan and Rawalpindi; the highest was in Faisalabad where the IDI value improved from 0.167 in 2002 to 0.66 in 2007, indicating major infrastructural transformation in this area. Another interesting finding was the distinctively high IDI values in city district Lahore indicating a clear divide between the primary and secondary cities in the study area.

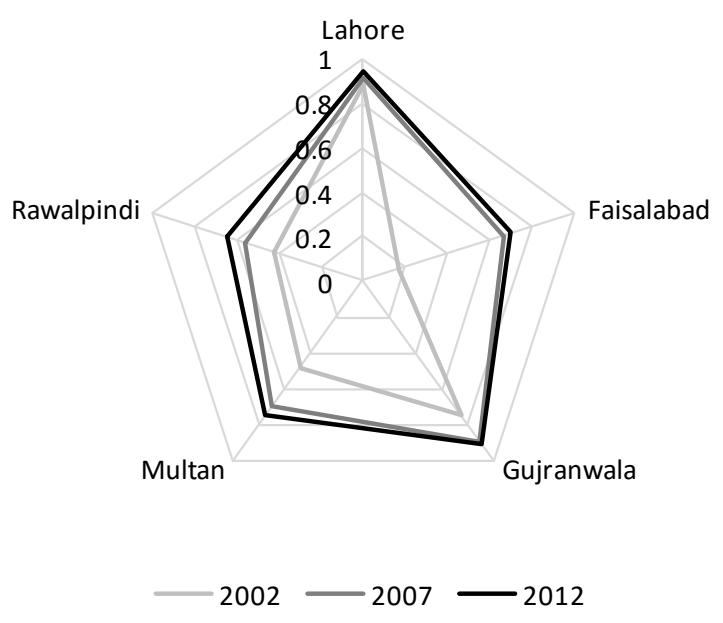

Figure 10. Spatiotemporal variability in IDI during 2002, 2007 and 2012 at city district scale (Tier-2) in Punjab, Pakistan.

The IDI values of 0.56, 0.75 and 0.8 in 2002, 2007 and 2012, respectively, were indicative of a progressive infrastructure development trend at the province scale (Tier-3) in the city districts of Punjab. It can be inferred that although some towns and city districts exhibit poor development conditions, the efforts of the government in terms of improving the infrastructure in city districts of the province have overall been quite fruitful. 


\subsection{Disparity analysis}

The results of $C_{v}$ at Tier-2 scale indicate that the infrastructure development gap reduced during 2007-2012 within all the city districts in the province, except Faisalabad where the disparity increased during this time (Figure 11). This result supports the findings of $I D I$ analyses (Section 4.3.) which revealed a poor situation of infrastructure development in Faisalabad. The highest development disparity was observed in city district Rawalpindi (30\%), followed by Faisalabad (23\%) and Multan (13\%) in 2012 suggesting that these areas require significant attention from the local government in terms of provision of infrastructure facilities across all the respective towns. The development variance in the primary city and city district Gujranwala was the lowest.

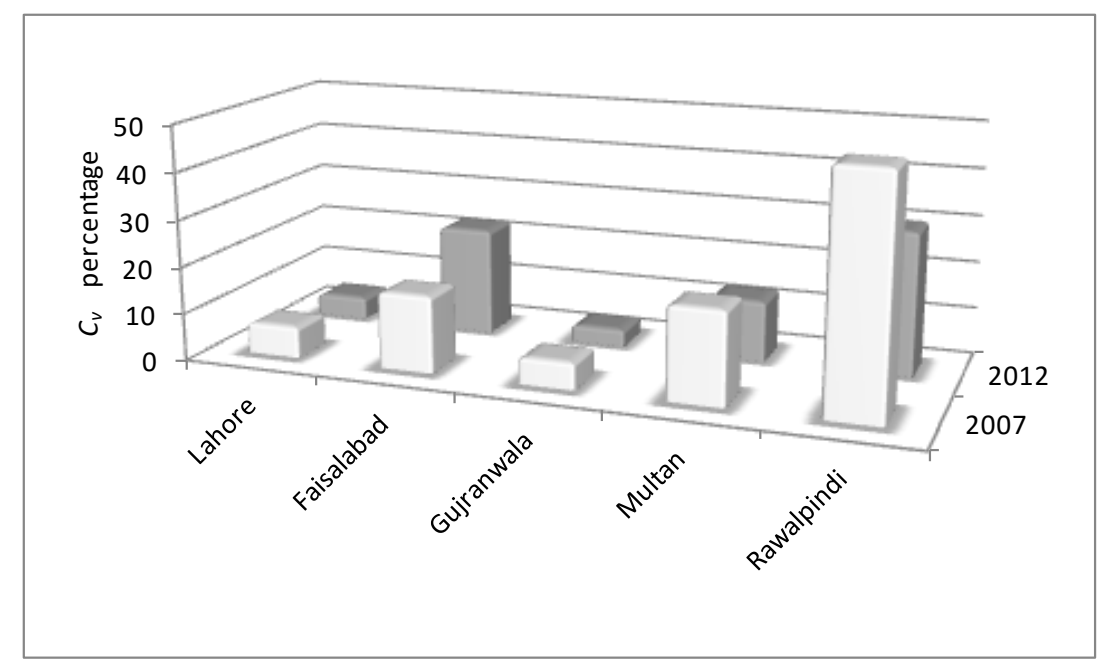

Figure 11. Infrastructure development disparity during 2007 and 2012 at city district scale (Tier-2) in Punjab, Pakistan.

At province scale (Tier-3) in the city districts of Punjab, a reduction in $C_{v}$ percentage from around 41 to 26 to 21 in 2002, 2007 and 2012, respectively, indicated a trend of improvement in infrastructure development (reduction in infrastructure development gaps) across the study area.

The infrastructure development trend significance during 2002-2007 and 2007-2012 was examined through paired sample t-test; Table 6 shows the results at city district (Tier-2) and province (Tier-3) scales. The results indicate that the infrastructure development improved in all the city districts during 2002-2012. Comparing the two time periods, higher development was observed in city districts Faisalabad, Gujranwala and Multan during 2002-2007, whereas Lahore and Rawalpindi exhibited increased development during 2007-2012. This variability indicates the disparity in development priorities during these time periods, which can be attributed to the difference in allocation and utilization of development funds in different city districts by the local governments.

A modest improvement in the primary city during 2002-2007 compared to other city districts indicates that the government priorities at that time focused on reducing the infrastructure development disparity in the entire study area. A higher infrastructure development improvement at province scale (Tier-3) in the city districts during 2002-2007 compared to that during 2007-2012 also justifies this argument (Table 6). These findings signify that although the past decade (2002-2012) witnessed notable infrastructure development in the study area, the period from 2002-2007 was better compared to 2007-2012 in terms of reducing the development inequality. 
Table 6. Infrastructure development trend significance at city district (Tier-2) and province (Tier-3) scales during 2002-2007 and 2007-2012 in Punjab, Pakistan.

\begin{tabular}{lll}
\hline Spatial scale & $2002-2007$ & $2007-2012$ \\
\hline City district & & \\
$\quad$ Lahore & -0.981 & $-3.846^{*}$ \\
Faisalabad & $-12.919^{*}$ & -0.661 \\
Gujranwala & $-7.410^{*}$ & -1.249 \\
Multan & $-3.895^{* *}$ & -2.376 \\
$\quad$ Rawalpindi & -1.384 & $-2.579 * *$ \\
$\quad$ & $-5.554^{*}$ & $-3.040^{*}$ \\
\hline Province & & \\
$\quad$ City districts of Punjab & (negative values denote that the later time exhibits improved infrastructure development compared to the initial time) \\
$*$ 1\% level of significance &
\end{tabular}

\section{Conclusions and recommendations}

The overall approach appears quite promising at examining the infrastructure development gaps at multiple spatial and temporal scales; it helps identify the regions requiring immediate attention in a particular development sector. The outcomes can guide the planners, policy makers and practitioners in devising policies and programs for a balanced development (Esfahani \& Ramírez, 2003; Lowder, 1991). In addition, the approach is robust with regard to embracing new dimensions to examine the development disparity, such as addressing the urban, peri-urban and rural development aspects individually, integrating additional infrastructure and socioeconomic development indicators, and others (Shen et al., 2012). The ability to adapt to the local conditions while making use of a variety of available data sets is another distinctive feature of the proposed approach.

In Pakistan, the policy programs are normally designed at national level which has been largely influenced by the MDGs. Administratively, all the cities are placed at the same hierarchy level without considering different functional dynamics, population sizes, and priority needs of each city. Moreover, impracticable approaches that are unable to identify local concerns have resulted in policy failures. The results of this study, however, indicate that the programs for improving water supply and sanitation facilities, and electricity provision have progressed substantially in Punjab, though further efforts for sustainable future development are still imperative. Local policy programs must be introduced rather than the national or provincial initiatives to properly and judiciously address the local issues.

A variable trend in infrastructure development was observed during both the time periods in the city districts of Punjab - the disparity was lower during 2002-2007 compared to 2007-2012 period. City district Lahore, which was categorized as a primary city in this study, led significantly in terms of infrastructure development; large population, stronghold of leading political parties, and expanding businesses/industries influence the allocation of funds and therefore, the city district is highly prioritized among others in the province. Interestingly, the level of infrastructure development in secondary cities was found to be somewhat related to the distance from the primary city; the farther a secondary city was, the less it was developed. Although the provision of improved water and sanitation facilities are prioritized in the city districts of Punjab, a high percentage of households are still awaiting improvement in these sectors. The infrastructure development disparity in the city districts implies that the situation might be worse in the rural areas. Policy programs centered on secondary cities need to be developed for uniform infrastructural development. Moreover, Lahore still requires special attention with regard to the provision of improved sanitation. Nevertheless, considering the constraints of the developing world, such as population rise, energy crisis and 
political instabilities, the local administration has been quite successful in providing infrastructure services; the situation has somewhat improved over time.

The proposed methodology can be further enhanced by incorporating more indicators and data points in time; the selection can be made based on the policy programs introduced in the past to estimate the success or failure of these programs. Other development sectors such as socioeconomic and environment can also be integrated in this multi-scale approach to represent a wider perspective for sustainable and balanced development. Moreover, this approach can be finetuned to suit the context of rural, regional, national and international infrastructural development.

\section{Acknowledgements}

The authors gratefully acknowledge the support from the Higher Education Commission of Pakistan, the Asian Institute of Technology, Thailand, and the University of Cambridge, UK for carrying out this research. We are thankful to the local field experts from Town Planning Wing and Metropolitan Wing of Lahore Development Authority, Rawal Town Municipal Administration, Urban Unit of Planning and Development Department, and City and Regional Planning Department of University of Engineering and Technology, Lahore, Pakistan for providing useful input to this research. We would also like to thank the anonymous reviewers for their constructive and invaluable suggestions.

\section{References}

Ahmad, E., Ludlow, S., \& Mahmood, M. (1989). Poverty, Inequality and Growth in Pakistan. The Pakistan Development Review, 28(4), 831-850.

Ahmad, N., \& Anjum, G. A. (2012). Legal and institutional perplexities hampering the implementation of urban development plans in Pakistan. Cities, 29(4), 271-277. http://doi.org/10.1016/j.cities.2011.07.006

Anand, S., \& Sen, A. (1994). Human development index: methodology and measurement. New York. Retrieved from http://econpapers.repec.org/RePEc:hdr:hdocpa:hdocpa-1994-02

Bhatti, S. S., Tripathi, N. K., Nagai, M., \& Nitivattananon, V. (2016). Spatial Interrelationships of Quality of Life with Land Use/Land Cover, Demography and Urbanization. Social Indicators Research. http://doi.org/10.1007/s11205-016-1336-z

Bhatti, S. S., Tripathi, N. K., Nitivattananon, V., Rana, I. A., \& Mozumder, C. (2015). A multi-scale modeling approach for simulating urbanization in a metropolitan region. Habitat International, 50, 354-365. http://doi.org/10.1016/j.habitatint.2015.09.005

Bobbitt, L., Green, S., Candura, L., \& Morgan, G. A. (2005). The development of a county level index of well-being. Social Indicators Research, 73(1), 19-42. http://doi.org/10.1007/s11205-0046165-9

Dadashpoor, H., Rostami, F., \& Alizadeh, B. (2016). Is inequality in the distribution of urban facilities inequitable? Exploring a method for identifying spatial inequity in an Iranian city. Cities, 52, 159-172. http://doi.org/10.1016/j.cities.2015.12.007

Duncan, D. T., Aldstadt, J., Whalen, J., White, K., Castro, M. C., \& Williams, D. R. (2012). Space, race, and poverty: Spatial inequalities in walkable neighborhood amenities? Demographic Research, 26, 409-448. http://doi.org/10.4054/DemRes.2012.26.17

Esfahani, H. S., \& Ramírez, M. T. (2003). Institutions, infrastructure, and economic growth. Journal of Development Economics, 70(2), 443-477. http://doi.org/10.1016/S0304-3878(02)00105-0

Everitt, B. S. (2003). The Cambridge dictionary of statistics (2nd ed.). New York: Cambridge University Press.

Gan, G., Ma, C., \& Wu, J. (2007). Data clustering: Theory, algorithms, and applications. Philadelphia: SIAM.

Ghaus, A., \& Pasha, H. (1996). Social development ranking of districts of Pakistan. The Pakistan Development Review, 35(4), 593-614.

Goodall, B. (1987). The Penguin dictionary of human geography. London: Penguin. 
Gordon, P., \& Richardson, H. (2000). Critiquing sprawl's critics. Washington D.C.: Cato Institute. Retrieved from http://www-bcf.usc.edu/ pgordon/pdf/pa365.pdf

Government of Punjab. (2001). Punjab Local Government Ordinance 2001. The Punjab Gazette. Islamabad.

Gutiérrez, A., \& Delclòs, X. (2016). The uneven distribution of evictions as new evidence of urban inequality: A spatial analysis approach in two Catalan cities. Cities, 56, 101-108. http://doi.org/10.1016/j.cities.2016.04.007

Habibi, S., \& Asadi, N. (2011). Causes, results and methods of controlling urban sprawl. Procedia Engineering, 21, 133-141. http://doi.org/10.1016/j.proeng.2011.11.1996

Hanif, M. A., Nadeem, R., Rashid, U., \& Zafar, M. N. (2005). Assessing pollution levels in effluents of industries in city zone of Faisalabad, Pakistan. Journal of Applied Sciences, 5(10), 1713-1717.

Hicks, D. A. (1997). The inequality-adjusted human development index: A constructive proposal. World Development, 25(8), 1283-1298. http://doi.org/10.1016/S0305-750X(97)00034-X

Holtz-Eakin, D., \& Schwartz, A. E. (1995). Infrastructure in a structural model of economic growth. Regional Science and Urban Economics, 25(2), 131-151. http://doi.org/10.1016/01660462(94)02080-Z

ICSU, \& ISSC. (2015). Review of Targets for the Sustainable Development Goals: The Science Perspective. Paris: International Council for Science (ICSU). Retrieved from http://www.icsu.org/publications/reports-and-reviews/review-of-targets-for-the-sustainabledevelopment-goals-the-science-perspective-2015/SDG-Report.pdf

Jaeger, J. A. G., Bertiller, R., Schwick, C., \& Kienast, F. (2010). Suitability criteria for measures of urban sprawl. Ecological Indicators, 10(2), 397-406. http://doi.org/10.1016/j.ecolind.2009.07.007

Jamal, H., \& Khan, A. (2007). Trends in regional human development indices. Karachi. Retrieved from https://www.researchgate.net/profile/Amir_Khan26/publication/237685055_TRENDS_IN_REGI ONAL_HUMAN_DEVELOPMENT_INDICES/links/54366e9b0cf2bf1f1f2b8971.pdf

Kessides, C. (1993). The contributions of infrastructure to economic development: a review of experience and policy implications. (C. Kessides, Ed.). Washington D.C.: World Bank Publications.

Khan, S. (2012). Vulnerability assessments and their planning implications: a case study of the Hutt Valley, New Zealand. Natural Hazards, 64(2), 1587-1607. http://doi.org/10.1007/s11069-0120327-x

Lee, S., Choi, C. G., \& Im, W. (2013). Metropolitan growth and community disparities: Insights from the state of New Jersey in the US. Cities, 30(1), 149-160. http://doi.org/10.1016/j.cities.2012.03.002

Lowder, S. (1991). The context of urban planning in secondary cities. Cities, 8(1), 54-65. http://doi.org/10.1016/0264-2751(91)90030-U

Lu, M., \& Chen, Z. (2004). Urbanization, urban-biased economic policies and urban-rural inequality. Economic Research Journal. Retrieved from http://en.cnki.com.cn/Article_en/CJFDTOTALJJYJ200406005.htm

Mangone, G. (2016). Constructing hybrid infrastructure: Exploring the potential ecological, social, and economic benefits of integrating municipal infrastructure into constructed environments. Cities, 55, 165-179. http://doi.org/10.1016/j.cities.2016.04.004

Mayo, S. M. (2012). Determination Of Urban Settlement Pattern For Optimal Regional Development In Punjab. University of Engineering and Technology. Retrieved from http://eprints.hec.gov.pk/9581/

McCrea, R., Shyy, T.-K., \& Stimson, R. (2006). What is the strength of the link between objective and subjective indicators of urban quality of life? Applied Research in Quality of Life, 1(1), 79-96. http://doi.org/10.1007/s11482-006-9002-2

Midhet, F. (2004). Development ranking of rural districts of Pakistan: A methodology to identity contextual determinants of safe motherhood. Population Association of Pakistan. Islamabad. 
Morris, M. D. (1979). Measuring the condition of the world's poor: The physical quality of life index. New York: Pergamon Press.

Nawaz-ul-Huda, S., Burke, F., \& Azam, M. (2011). Socio-economic disparities in Balochistan, Pakistan-A multivariate analysis. Geografia: Malaysian Journal of Society and Space, 7(4), 3850.

Njoh, A. J. (2003). Urbanization and development in sub-Saharan Africa. Cities, 20(3), 167-174. http://doi.org/10.1016/S0264-2751(03)00010-6

Pelling, M. (2003). Tracing the roots of urban risk and vulnerability. In The vulnerability of cities: natural disasters and social resilience. London: Earthscan.

Punjab Bureau of Statistics. (2004). Multiple Indicator Cluster Survey 2003-2004. Lahore. Retrieved from http://www.bos.gop.pk/publicationreports

Punjab Bureau of Statistics. (2009). Multiple Indicator Cluster Survey 2007-2008. Lahore. Retrieved from http://www.bos.gop.pk/publicationreports

Punjab Bureau of Statistics. (2011). Multiple Indicator Cluster Survey 2011. Lahore. Retrieved from http://www.bos.gop.pk/publicationreports

Punjab Bureau of Statistics. (2015). Punjab Development Statistics 2015. Lahore. Retrieved from http://www.bos.gop.pk/publicationreports

Rana, I. A. (2014). Rural urban development dispsarity in Lahore city region: Policy implications for regional development. Asian Institute of Technology, Thailand.

Roberts, B. H. (2014). Managing systems of secondary cities: Policy responses in international development. Brussels: Cities Alliance/UNOPS. Retrieved from http://www.citiesalliance.org/node/4978

Roberts, B., \& Hohmann, R. P. (2014). The Systems of Secondary Cities: The neglected drivers of urbanising economies. CIVIS: Sharing Knowledge and Learning from Cities, 7. Retrieved from http://www.citiesalliance.org/sites/citiesalliance.org/files/CIVIS SECONDARY CITIES_Final.pdf

Roberts, B., \& Kanaley, T. (2006). Overview: Urbanization and sustainable development. In B. Roberts \& T. Kanaley (Eds.), Urbanization and sustainability in Asia: Case studies of good practice (pp. 1-13). Mandaluyong: Asian Development Bank.

Rondinelli, D. (1983). Secondary cities in developing countries: Policies for diffusing urbanization. Retrieved from http://www.popline.org/node/398273

Rouf, M., \& Jahan, S. (2007). Spatial and temporal patterns of urbanization in Bangladesh. Urbanization in Bangladesh: patterns, issues and approaches to planning. Dhaka. Retrieved from www.bip.org.bd/SharingFiles/journal_book/20130718114655.pdf

Saaty, T. (1980). The analytic hierarchy process: planning, priority setting, resources allocation. New York: McGraw.

Shen, L., Jiang, S., \& Yuan, H. (2012). Critical indicators for assessing the contribution of infrastructure projects to coordinated urban-rural development in China. Habitat International, 36(2), 237-246. http://doi.org/10.1016/j.habitatint.2011.10.003

The Whoqol Group. (1998). The World Health Organization quality of life assessment (WHOQOL): Development and general psychometric properties. Social Science \& Medicine, 46(12), 15691585. http://doi.org/10.1016/S0277-9536(98)00009-4

Theil, H., Raj, B., \& Koerts, J. (1992). Henri Theil's Contributions to Economics and Econometrics: Econometric theory and methodology. Vol. I. Dordrecht: Kluwer Academic Publishers.

Triantaphyllou, E. (2013). Multi-criteria decision making methods: a comparative study. Dordrecht: Kluwer Academic Publishers.

UNDP. (2015). Human Development Report 2015. Work for Human Development. Retrieved from http://hdr.undp.org/sites/all/themes/hdr_theme/country-notes/MEX.pdf

Williamson, J. (1965). Regional inequality and the process of national development: a description of the patterns. Economic Development and Cultural Change. Retrieved from http://www.jstor.org/stable/1152097 
Yitzhaki, S. (1983). On an extension of the Gini inequality index. International Economic Review. Retrieved from http://www.jstor.org/stable/2648789 